\section{Original Communtrations.}

\author{
THE ANTECEDENTS OF CANCER AND \\ THE LOCALISATION OF DISEASE.
}

\section{By Charlas H. Moore, F.R.C.S., Surgeon to the Middlesex Hospital.}

There is something startlingly decisive in the title of the Croonian Lectures for the present year. For, in undertaking an exposition of the "Localisation of Disease", an author assumes, or designs to show, the existence of disease before its establishment in an organ. Whether morbid processes begin as separate local entities or are induced by extraneous causeswhether, in fact, diseases are primarily local or general-is one of the most important questions of the day. It was accordingly with great interest that I expected, and with great pleasure that I heard, Dr. Sieveking's lectures on this subject.

The increasing exactness of our clinical and pathological investigations is having this effect, that diseases are more and more attributed to mechanical and intelligible causes, and are, consequently, divested of their former mysterious character. When pneumonia originates from the intrusion of trichinæ into the lung (Sieveking, on Thudichum, BRITISH Mrdical Journal, March 31st, 1866, p. 326), or peritonitis from the rupture of an obstructed thoracic duct (Cayley, Pathological Society, March 20th, 1866), the definiteness of the local cause in each case satisfactorily accounts for the localisation of the inflammation. If there are other diseases, the occasion of which is less obvious than these, experience thus far appears to justify the expectation that, by methods better adapted for the investigation than we yet employ, we shall be able eventually to penetrate into their occult origin, and to observe the direct action of each cause in the production of its morbid effect.

Whether this shall be so or not, it is surely premature to adopt the principle that all disease, not having an ascertained local cause, is of general origin, and thus to fix its source, though yet untraced, elsewhere than at the seat of the morbid process itself.

Of some diseases it is undoubtedly true, that their cause is derived from a remote part; but it is not thereby shown that all diseases thus originate. Least of all is it so shown of cancer. Whatever mischief the circulation of beer may inflict upon the kidney, or that of gin upon the liver; in whatever way malaria affects the spleen, or grindstone grit the lung (Greenhow, Transactions of Pathological Society, vol. xvi, p. 59); the cause in each case reaches the organ, acts in it, and acts throughout it. In cancer, on the contrary, neither is a prior cause demonstrable apart from the situation of the first tumour, nor is the outbreak of the disease common to the whole of an organ. The various anatomical relations of a cancerous tumour may indeed make it a cause of disease extraneous to itself; and so a mammary cancer may cause pleurisy, as trichinæ do pneumonia; or it may spoil the axillary glands, projecting its constituent particles by a convenient tube, as steel dust produces asthma. Thus, even cancer may be the remote source of a new disease; but the principle that all disease has a remote or general origin cannot be applied to the primary cancerous tumour itself. It is a local error of nutrition, for the general cause of which (if any exist) the eridence hitherto accepted is doubtful or inapplicable.

It is not from a presumptuous desire to criticise that I thus write; but in order to be aided in correctly stating my views on this subordinate subject of cancer. I have been somewhat unforta. nate in the notice of my doings with which the press has sometimes favoured me. On one oocasion an Introductory Address of mine, on the principles and objects of the life of a modern medical man, was reported to have been devoted to a contrast of Arabian and European surgery. To my great surprise, my paper read at Leamington in August last was thus referred to in a weekly journal ; and my request to have so important a misrepresentation corrected was not complied with.

"Mr. Moore contended that no constitutional antecedents affected it; but that, when the disease appeared, its elements existed throughout the system, so that the extirpation of the cancer did not eradicate the disease, the elements of which still existed, and would crop out sooner or later." (Reader, Aug. 12th, 1865.)

My friend Dr. Sieveking, too, appears to me to have misunderstood what I have written in my Antecedents of Cancer; and he had certainly received an impression opposite to that which I intended to convey, when, in his generous notice of that essay, he thus expressed himself.

"After all, the author admits a constitutional predisposition; but he is unable to reconcile his experience of the progress of the disease with the ordinary terminology of science, which would term it morbid, though it disguise itself under the semblance of health." (British Medical Journal, March 24, 1866, page 300.)

I am at a loss to account for so strange a misconception of my meaning as is contained in these two statements of the Croonian Lecturer. That cancer is a disease, is morbid, that it is so throughout its progress, from its beginning to its end, I have no doubt. But that the persons in whom cancer ocenen have had any prior constitutional ailment, to which that occurrence is due, I do doubt. As the disesese has presented itself to me, its first aspect is that of faulty texture only, and not of one having any remote or general cause. Regarding justly the obscurity out of which cancer springs, Dr. Sieveking abstains from a positive statement as to its causation, and he includes it only generally among the diseases which have a constitutional source. His opinion is so commonly approved, that he had no need, even if his limits allowed him, to demonstrate the grounds of it; but I am anxious to be myself cleared of holding it. That opinion appears to me to be unproved, to have arisen from confounding the mere mechanical progress of the established disease with its antecedents, and to be subverted by various facts and considerations which I adduced in $\mathbf{m y}$ paper. Accordingly, I do not admit any constitutional predisposition, unless (though I deny it) a general conclusion is involved in the exceptional fact that cancer, self-originated in one generation, is reproduced in succeeding ones. The very large majority of cancers spring up without traceable hereditary influence; and the very large majority of such instances of the disease, which are thus independent of the ancestry of the person affected, are also not transmitted to any of the offspring. For three patients affected with cancer, ninety-seven parents (who yet have a cancerous relative) and ninety-seven children go free. So little is any constitutional character of cancer discoverable in its inheritance.

Lest I should have failed to express in my own terms the opinion as to a constitutional predisposi- 
tion which is sometimes entertained, I will quote the words of the last writer on the subject, Paul Broca. In the first volume of his new work on Tumours, he recites two cases in which the growth of cancer is alleged to have followed an injury. In one ease, the disease was first noticed soon after a severe blow on the heel; in the other, after prolonged friction, combined with an injury, of the pubes. The author thus argues on these facts.

"In accounting for cases of this kind, we are obliged to admit the existence of a previous disposition in the economy, before the local accident which determined the formation of the tumour. The diathesis hovered, as it were, over the organism; and, though not yet manifested,it would doubtless sooner or later have established itself spontaneously in some organ or other. The local cause, provoking a morbid action at a particular point, and leading to the secretion of blastema there, drew to that point the action of the diathesis. Soon the secretion of the traumatic blastema was followed by that of a cancerous blastema, and the tumour was developed under the double influence of a local and of a general cause.

"Whatever be the value of this interpretation, it is certain that these two kinds of causes, local and general, may be associated, and may preside over the development of the same tumour. Side by side with such cases as I have last cited, where this double intervention is evident, there are others in which the two kinds of influence are equally probable, or equally doubtful. Amidst health the most flourishing, and in a part which has never suffered any appreciable injury, one isolated tumour spontaneously forms. In such a case, the observer is obliged to await the event in order to know whether the tumour constitutes the entire malady, or if it be only the product and manifestation of a diathesis.

"The diatheses which preside over the development of tumours" "are almost always the creatures of reason (êtres de raison), for they possess no proper symptom by which to reveal themselves before the appearance of the tumour. It is from the necessity of theory alone that we admit their existence, because without them it is impossible to explain the phenomena we attribute to them." (Broca, Traité des Tumeurs, 1866, tome i, p. 145 .

Against this notion of an antecedent cumulative cause of cancer, apart from the site of the first tumour, and distinct in time from its appearance, I ventured to address my arguments at Leamington. To speak of a diathesis coexistent with flourishing health, I cannot but deem a groundless assumption; and $I$ still find it exercising a disastrous influence, when it begets uncertainty and excuses delay in the early management of the primary tumour.

\section{THE CITRIC, ACETIC, AND CARBOLIC ACIDS IN CANCER.}

By John Barclay, M.D., C.M., Banff, N.B.

THE appearance in the Lancet of March 24th, 1866, of the report of a case of Cancer of the Tongue treated by Citric Acid, suggests to me the propriety of my publishing my experience of the same remedy, as also that of the acetic and carbolic acids, in the same class of cases.

In the beginning of September of last year, a paragraph was pointed out to me in a newspaper setting forth the wonderfully beneficial effects which had attended the use of citric acid as a remedy in a case of cancer; but I did not think of trying it, until a patient labouring under a large and excessively painful and cancerous tumour of the neck, behind the angle of the jaw, which from its size, situation, and the extent of its attachments, held out no hope of its successful removal by the knife, requested me to allow her to make a trial of the acid, as she said her clergyman had strongly recommended her to do so. I at once assented, thinking it could have little effect either for good or for harm. But when I called in a few days after, I was somewhat surprised to find that since she had applied a lotion composed of a drachm and a half of the acid, dissolved in eight ounces of water, she had had almost no pain in the growth. This I was the more astonished to hear, as nothing of the anodyne class seemed to have 'afforded the slightest relief from the pain before, with the exception of the hypodermic injection of morphia, and even this, she said, did not remove the pain so effectually as the citric acid lotion; and besides, the relief from the latter was much more permanent. This treatment was continued for some weeks, with the effect that the patient improved considerably in looks, health and spirits ; and to show if this was really due to the change of remedy, I ordered her to discontinue the wash for a week, during which period of omission the pain returned with as great severity as before, compelling the patient to resume the application, which again brought relief along with it. It now occurred to me, remembering the solvent power of acetic acid over cancer cell walls, to try what effect that acid would have when applied tò the tumour. By this time the skin had begun to give way, and a sore to develope itself on the surface of the growth. I therefore ordered vinegar to be applied, and was glad to find that this controlled the pain quite as well as the citric acid had done before. Dr. Manson, the Senior Surgeon of Chalmers' Hospital, in this place, who had used the citric acid lotion with equally beneficial results in another case of cancer (this time of the breast, and totally unsuited for excision from its extent, adjacent glandular enlargement, and the length of time it had existed) now changed it for the vinegar application, and he had no reason to be disappointed, for he found that its anodyne power was equal to that of the citric acid, and also that it possessed advantages which the acid formerly used by us possessed in a very much more slight degree. In the case of the wounds in the breast, which were numerous, and all partaking of the characters of cancerous sores in a most marked degree, it was noticed that after the application of the citric acid, the "thick, serrated and everted edges" did not seem quite so thick, serrated and everted as before, but looked thinner, softer and with less induration around them. But, and as I hoped would turn out to be the case, the application of the acetic acid lotion, gradually increased in strength from that of common vinegar upwards, produced in this way a much more marked effect, for the edges began to thin down much more rapidly, granulations of a seemingly healthy character arose in the centre of the wound, all fetor disappeared from the discharge, and even attempts at cicatrisation began to take place, sufficient in several of the smaller ulcers to close them in altogether.

The acetic in varying degrees of strength had now been used for a month in both cases, and looking back over this period, and over the month during which the citric acid had been used, to the condition of both patients previous to the use of these remedies, we were of opinion that not only had their state of health, and the appearance of the disease in each, not become worse, but that both had most sensibly improved. Both patients ate and slept much better than before, and were able to go about their usual household occupations with ease and comfort. The tumour in the neck had become decidedly less, there were attempts at a skin-forming 